While of course according the greatest respect to the work of so eminent a scientist as Sir Edward, I feel, as a clinician, that his findings do not quite fit in with all the known facts concerning hysteria as it occurs in the field. In the first place, Sir Edward stresses the occurrence of epileptiform fits among the symptoms, unconsciousness lasting sometimes half an hour up to 36 hours; yet I must say at once that such fits are not a prominent feature of canine hysteria in the field. Is the condition produced by Mellanby that which a veterinary surgeon recognizes clinically as hysteria, or is it some other condition?

I personally have always held that canine hysteria had an alimentary aetiology, and I favoured a toxic rather than a deficiency factor. The recent experiments appear to confirm the first belief and incriminate treated wheat flour as the actual cause. It is alleged that dogs fed on a diet containing agenized flour will contract hysteria, while control animals fed on the same diet but with the cereal portion not agenized will not do so. It is said that $90 \%$ of the flour consumed in the country is agenized, and it is scarcely conceivable that animals, whether consuming bread or biscuits, can avoid consuming agenized flour. The racing greyhound, of which there are many thousands, is normally fed (in times of abundance) upon stale bread soaked in gravy, mixed, of course, with other foodstuffs. The majority of this must have been agenized.

It is pertinent therefore to ask why all these animals up and down the country have not been in a perpetual state of hysteria. Yet the occurrence of hysteria is comparatively rare and very sporadic. Can it be contended that an immunity is acquired from the consumption of bread? If so, why are only some and not all immunized? It is certainly true that recurrence in the same animal is most unusual.

It has been my experience, and that of many others, not excluding Sir Edward, that to change the food or its source has been practically all that was needed to abort an outbreak in a kennel or stop an attack in an individual. This must have meant, in innumerable cases, changing from one make of bread or biscuit to another make; in effect to feed on food made from an entirely different consignment of flour. This led to my strong belief that the aetiological factor was possibly a parasite of wheat or a mould on the stale bread, especially as Russell Greig had proved (in 1922) that what he then called epileptiform convulsions could arise from the presence in the alimentary tract of a wheat parasite-Tilletia tritici (bunt or stinking smut). Such a theory is not yet disproved.

Although it is claimed that the real incidence of hysteria occurred at about the same time as the introduction of the agene process, yet there are in the literature references to hysteria made earlier than this, and $I$ have known of the disease almost as long as $I$ have been in practice-now 35 years. It is open to doubt if hysteria has really increased from the very early days when it was first reported, since it may only be that the diagnosis has been more complete. In the kennel of some 300 greyhounds over which I have veterinary control I have not had to report a single case of hysteria for more than a year. The last attack-in about half a dozen dogs-occurred about two years ago. I have seen about seven cases in private practice during the past year. In the meantime I am making inquiries in other countries, which may throw light on the subject. It would be enlightening to know the total number of dogs employed in Mellanby's experiments and what was the actual percentage which contracted hysteria.

There are other issues, too, which could be raised if space would permit. Anxiety has been expressed in the lay Press and elsewhere that humans should be obliged to consume food which is proved to be unsafe for dogs. Is it assumed that such food would produce hysteria or epileptiform fits in man? So far as I am aware there seems as yet little evidence that the general health of mankind has suffered in consequence; at least I am not aware that either of the above conditions has been on the increase in man.-I am, etc.,

London. N.W.11.

Hamilton KiRK.

\section{Mental Deficiency}

SIR,-Dr. Mary N. M. Paulin (Jan. 4, p. 31), in drawing attention to an inaccuracy in "Any Questions" under the heading "Mental Deficiency" (Dec. 14, 1946, p. 929), herself makes an inaccurate statement. I had hoped that by this time some more authoritative person than myself would have drawn attention to these inaccuracies, but as they seem to be likely to be passed unchallenged I feel I must do so, as failure to realize their significance may cause distress to many parents. The question is somewhat complicated, so that for the sake of brevity I shall mention only the main points. Dr. Paulin states that "the Education Act of 1944 gives to local authorities the power to order special educational treatment for mentally deficient children. . . " [The italics are mine.] It should be noted that the phrase "mentally deficient" has been abolished from the educational world by the Act and should not be applied to educable children. Those who are backward but educable are now known as educationally subnormal.

Referring to the original question (Dec. 14, 1946), I have difficulty in understanding it. If the child is an "idiot" as stated in the question he is ineducable. The local education authority cannot send him to a special school. It is their clear duty to refer him to the local (mental deficiency) authority. If he is educable he is certainly not an "idiot." (An idiot is a person who is unable to guard himself against common physical dangers.) Referring to your answer (Dec. 14, 1946), I again find a difficulty. If a child is "certified as a mental defective under the Mental Deficiency Acts of 1913 and 1927 " he is beyond the jurisdiction of the local education authority and cannot be sent to a school, ordinary or special. The local (mental deficiency) authority can send him to an institution at the instance of the parent or guardian, or under certain other conditions such as neglect.

If the word "idiot" is used inadvertently in the question and should be replaced by the words "educationally subnormal," then it is the duty of the local education authority to provide special treatment in an ordinary school or, if they think desirable, in a day or residential special school (unless the parent makes other suitable arrangements). If the child is ineducable it would be not only illegal but also most undesirable in the interests of other children to allow him to attend school. If he is educationally subnormal it is essential that he should have appropriate educational treatment, and, if the backwardness is very marked, it is unlikely, as is suggested in your answer, that such education could be provided in a village school.

The Education Act of 1944 allows for appeal by the parent to the Minister of Education against the decision for special educational treatment or for reference to the local (mental deficiency) authority. It should be realized that in this and various other ways the interests of the child and the rights and feelings of the parents are very carefully protected by the Acts. Various circulars issued by the Ministry have emphasized this. For the educable there is in many areas a shortage of accommodation in day special schools, and throughout the country there is very serious lack of accommodation of residential special schools ; and for the ineducable there is gross lack of institutional accommodation. Hence it is in only very clear-cut cases that an educational authority is likely to want to send an educable child to a special school or a local (M.D.) authority to want to send an ineducable child to an institution.-I am, etc.,

Nottingham.

A. A. E. Newth.

\section{Age Limit in Advertisements}

SIR,-I was interested to read the letter from "Dunmar" (Dec. 28, 1946, p. 1007) on the age limit for whole-time posts under the various ministries. There appeared a short time ago an advertisement for a regional medical officer under the N.H.I. Having reached the ripe old age of 50 in March I found I was six months too old for it. The fact that I was too old was due entirely to the four years I spent in the Army, 1914 to 1918 , before beginning my mecical training. I was then, in common with thousands of others, labouring under the delusion that in fighting for my country I was more fitly serving it.

In the 1930s a similar post was advertised for Scotland, the age limit then being 35, again debarring ex-Service men. Last year there was a vacancy in Scotland again, the age limit being raised to 45 . This still excludes men like me, but also. proves that the age limit is capable of adjustment.

I sent for an application form for the posts advertised in November, and was much interested to read that not only did my old age count against me, but the disgrace of never having been captain of the school, never having been even a prefect had put me beyond the pale. I received my early education among the very men who are patients under the N.H.I., and 